\title{
Eine Berichtigung zu Dr. med. R. Puppels Arbeit:
}

„Über Streptokokken in der Mileh und im Säuglingsstahl.“

Von

Dr. med. vet. W. Ernst, stëdt. Amtstierarzt.

In einer ausgezeichneten Arbeit „Über Streptokokken in der Milch und im Säuglingsstuhl“" zitiert Dr. med. R. Puppel bei Besprechung der Morphologie der Mastitisstreptokokken meine Arbeit „Über Milchstreptokokken und Streptokokkenmastitis" und führt aus, daB die Darlegungen in meiner Arbeit nicht ganz mit den Befunden Sr. Walls und seinen bzw. Tierarzt Gohrs Untersuchungsergebnissen übereinstimmten.

Ich soll auf Grund von 1840 Milchuntersuchungen behauptet haben, daB die Mastitisstreptokokken sich durch Staketform auszeichneten, und daB man mit Hilfe dieser Form die Diagnose schon aus dem Ausstriche der frischen Milch stellen könne.

Entgegen diesen Befunden habe Sv. Wall drei verschiedene Formen feststellen können.

1. Lanzettförmige Diplokokken mit dicker Schleimhülle,

2. lanzettförmige Diplokokken ohne Schleimkapsel in langen Ketten und

3. staketförmige Streptokokken in langen Ketten.

Tierarzt Gohr habe zwar in ersten Aufstrichen von Mastitiseiter meine Befunde durch Auffinden von Staketform bestätigen können und auch in ersten Kulturgenerationen die Staketform erhalten gesehen, später aber wie auch Puppel selbst und wie Sv. Wall manchmal in Mastitiseiter ausschlieBlich lanzettförmige Streptokokken gefunden.

Um nun weitere Mißverständnisse nicht aufkommen zu lassen, stelle ich in folgendem die Ansicht Puppels richtig. 
Diese Richtigstellung erscheint mir notwendig, weil ich bei dem praktischen Wert der seinerzeit von mir niedergelegten Sätze eine $A b$ schwächung derselben in irgend einer Form nicht für wünschenswert halte.

Ich habe in meiner Arbeit darauf hingewiesen, daß die "tierische" Form des Streptococcus, die der Mikrobe einige Zeit nach der Infektion in erkrankten Organen annimmt, in vielen Fällen eine Unterscheidung ermöglicht zwischen Streptokokken, die aus dem erkrankten Euter stammen, und solchen, die nachträglich in der Milch gewachsen sind. - Ferner habe ich betont, daB es auf Grund dieser Formunterschiede möglich ist, in Sedimentausstrichen von Marktmilch, im Falle die Formmerkmale des ,tierischen" Streptococcus typisch sich darbieten, zu erkennen, daß Wilch euterkranker Tiere der Mischmilch beigemolken ist; nicht aber ist es beim Fehlen dieser Formmerkmale angebracht zu schließen, daB dies nicht geschehen ist. - Der positive Befund ist beweisend, der negative aber nicht ausschließend.

Bei den 1840 von Puppel zitierten Untersuchungen handelt es sich um Marktmischmilch vieler Kühe. Die Befunde Sr. Walls, Puppels und Gohrs sind in Ausstrichen von Mastitissekret gemacht. Hätte der Autor meine Arbeit vollständig gelesen, so hätte ihm nicht entgehen können, daB ich auf Grund von Ergebnissen bei 1697 Milchproben aus einzelnen Eutern (348 kranke, 34 rerdächtige) und von 528 Proben aus einzelnen Eutervierteln (276 kranke) ebenso wie Staeheli, Zschokke, Wall u. a. auf die Variabilität der Mastitisstreptokokken hingewiesen habe. - In dem Kapitel: „Die Galtstreptokokken unter sich" habe ich die Diplokokkenform öfters neben den Brevis - und Longusformen erwähnt. Für die Marktmilchbeschau haben aber Wuchsformen, die mit Milchsäurestreptokokken und ähnlichen harmlosen Saprophyten verwechselt werden können, keine Bedeutung, desto wichtiger aber sind die Formen, aus denen mit absoluter Sicherheit auf das Beimelken mastitiskranker Euterviertel zu schlieBen ist.

Die einschlägigen Stellen meiner Arbeit lauten:

S. $420, \mathrm{Bd}$. XX der „Monatshefte für praktische Tierheilkunde“: „,Ich will nicht behaupten, daß ein Streptococcus in Milch, der diese Formeigentümlichkeiten nicht hat, kein Galtstreptococcus ist, oder nicht aus dem Euter stammen könnte, und daB nicht unter abnormen Bedingungen, z. B. Züchtung bei $37^{\circ}$ in roher Milch oder im Blutserum, die vorhandenen Streptokokken Formänderungen durchmachen könnten, die unter Umständen den Formen des tierischen Streptococcus ähnlich sind, aber für die normalen Verhältnisse der Trinkmilchbeschau sind die morphologischen Besonderheiten der tierischen Streptokokken absolut sichere 
lirkennungszeichen, wie die Kontrollen in den betreffenden Stallungen stets ergaben."

S. 423: „55 kranke Viertel zeigten den Str. brevis, 32 den Str. longus, bei 47 lieB sich der Erregernur in Diplokokkenformerkennen."

S. 428: „In bestimmten morphologischen Merkmalen: Querstellung der Teilglieder, kapselähnlicher Umhüllung und anderem haben wir ein Mittel, aus dem Euter stammende Streptokokken von nachträglich in der Milch gewachsenen Stämmen zu unterscheiden. - Diese Unterscheidungsmerkmale lassen, wenn vorhanden, im Sedimentaufstrich von Handelsmilch erkennen, dab die Streptokokken aus einem infizierten Euter stammen. Sind Streptokokken in Milch, denen diese Merkmale fehlen, so ist nicht auszuschlieben, daB auch diese eventuell Galtstreptokokken sind, es fehlt jedoch der Beweis, daß Sekret streptukokkeneuterkranker Kühe beigemolken ist." 